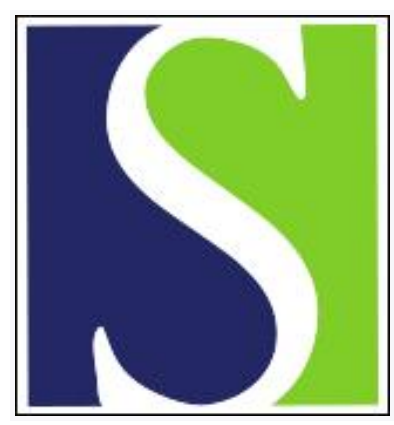

Scand J Work Environ Health 2003;29(4):304-313

https://doi.org/10.5271/sjweh.735

Issue date: Aug 2003

Medical costs of fourteen occupational illnesses in the United States in 1999

by Leigh JP, Yasmeen S, Miller TR

Affiliation: Department of Epidemiology and Preventive Medicine, School of Medicine, TB 168, University of California at Davis, Davis, California 95616-838, United States. pleigh@ucdavis.edu

Refers to the following texts of the Journal: $2001 ; 27(3): 161-213$ 2002;28(1):25-32

The following article refers to this text: 2018;44(6):601-612

Key terms: economics; job; medical cost; occupational illness; Occupational Safety and Health Administration; OSHA; United States

This article in PubMed: www.ncbi.nlm.nih.gov/pubmed/12934724 


\title{
Medical costs of fourteen occupational illnesses in the United States in 1999
}

\author{
by J Paul Leigh, PhD, ${ }^{1}$ Shagufta Yasmeen, $M D,{ }^{2}$ Ted RMiller, PhD ${ }^{3}$
}

\begin{abstract}
Leigh JP, Yasmeen S, Miller TR. Medical costs of fourteen occupational illnesses in the United States in 1999. Scand J Work Environ Health 2003;29(4):304-313.
\end{abstract}

\begin{abstract}
Objectives This study estimated the annual medical costs associated with 14 occupational illnesses in the United States in 1999.

Methods National data sets collected by the National Center for Health Statistics, the Health Care Financing Administration, and the Agency for Healthcare Research and Quality were aggregated and analyzed. The cost assessment began with estimates of national health expenditures. These included categories for hospital care, professional services, nursing homes, and medical products, including drugs, administration, public health activities, research and construction. The total disease burden was assessed from estimates of hospital days and number of outpatient visits. The occupational disease burden was assessed by multiplying the total disease burden by a given percentage of the proportionate attributable risk for the disease in question. The occupational burden was then combined with costs for each disease. Adjustments were made for unique inpatient and outpatient costs.

Results In the preferred model, the 14 diseases generated USD 14.5 billion in medical costs in 1999. Roughly USD 10.7 billion was attributed to men and USD 3.8 billion to women. The diseases generating the most costs were as follows: circulatory diseases in the age group 24-64 years (USD 4.7 billion), cancer (USD 4.3 billion), chronic obstructive pulmonary disease (USD 2.2 billion), and asthma (USD 1.5 billion). A sensitivity analysis generated alternative estimates. An upper age limit of 74 years increased the circulatory disease estimate by USD 3.7 billion. The range of the sensitivity analysis was USD 9.6-19.7 billion.

Conclusion This study significantly improves over the methodology of previous literature. Our methods were transparent. Occupational illnesses were a major contributor to the total cost of medical care.
\end{abstract}

Key terms economics, jobs, Occupational Safety and Health Administration.

Two closely related studies have estimated the national costs of occupational illness to be between USD 19 and 30 billion for five fatal diseases and many nonfatal conditions combined in 1992 (1, 2). Since the publication of these two studies, several suggestions for extensions of the analysis have been made, and the limitations have been discussed. Chief among the suggestions are requests for more recent data and separate analyses for men and women. Notable limitations are the many dis- eases, such as ulcers and depression that are ignored, the limitation of circulatory disease deaths to persons under 65 years of age, the combination of chronic obstructive pulmonary disease (COPD) and asthma into one disease estimate, the lack of adjustment to reflect varying costs for inpatient and outpatient care, and the questionable procedure used to account for age limits (eg, 25-64 or $\geq 25$ years) in data on hospital days.

1 Department of Epidemiology and Preventive Medicine, School of Medicine, University of California at Davis (UCD), Davis, California, United States, and Center for Health Services Research in Primary Care, UCD Medical Center, Sacramento, California, United States.

2 Department of Obstetrics/Gynecology and Internal Medicine, University of California at Davis, Davis, Sacramento, California, United States.

3 Pacific Institute for Research and Evaluation, Calverton, Maryland, United States.

Reprint requests to: Dr J Paul Leigh, Department of Epidemiology and Preventive Medicine, School of Medicine, TB168, University of California at Davis, Davis, California 95616-838, United States. [E-mail: pleigh@ucdavis.edu] 
This study used data from 1999, combined with proportionate attributable risks (PAR) from a recent study (3), to produce estimates for 14 diseases. Each of the preceding lists of the suggestions and limitations has been addressed. We estimated medical costs because these receive the greatest attention in the national debate on the economics of medical care. We focused on estimates generated with PAR since they comprise roughly $90 \%$ of all direct costs of occupational illnesses $(1,2)$. We did not use data on job-related illnesses recorded in the annual survey of the Bureau of Labor Statistics (4). The cost estimates for the data require an incidence methodology entirely different from the PAR prevalence method.

We used the proportionate attributable risk (PAR) model to estimate these costs. The PAR is simply an estimated percentage of the mortality or morbidity of a disease attributed to a given factor, such as smoking or work conditions. Our PAR refer to work conditions. For example, if the PAR for COPD is $15 \%$ for men and toxic work conditions are eliminated, the prevalence of COPD would drop by $15 \%$ for men. Note that the PAR for various factors may add up to more than $100 \%$. It could be, for example, that some cases of COPD require both toxic work conditions and smoking. If either factor were eliminated, the prevalence of the disease would decrease. Our PAR were drawn from Nurminen \& Karjalainen (3).

\section{Subjects and methods}

We used the prevalence of occupational disease to measure the overall burden. Prevalence may overstate or understate the disease burden given that it does not account for time trends; it is merely a snapshot at a point in time (1999). An alternative method-using incidence-creates greater problems, however. The incidence method would necessitate forecasting the future course of disease, treatment, and cost. Most cost-of-illness studies (whether or not occupational) have preferred the prevalence method precisely because it allows the analysis of reliable data that are available and requires fewer forecasting assumptions than the incidence method (5-19). If future courses of disease, treatment, and costs were known, cost estimates using the prevalence and incidence methods would differ depending on the time trend of disease and whether cost calculations include a real interest rate. If the disease becomes more prevalent over time (asthma), then the incidence costs are less than the prevalence costs. If it becomes less prevalent (circulatory), then the incidence is less than the prevalence. If a real interest rate is used in the incidence calculation, then the incidence costs are less than the prevalence costs (2).

Medical costs include payments to hospitals, physicians, drug companies, nursing homes, and vendors of medical supplies. Our "top-down" approach to estimate medical costs was similar to that of Rice et al (7) and Leigh et al (6). The estimates relied on a ratio involving hospital days multiplied by national estimates of medical spending. (See equation 1 on page 306.) The numerator of the ratio was hospital days attributed to a given disease and the denominator was the total number of all hospital days attributed to all diseases and injuries. The ratio was a percentage of all hospital days for all disease and injury attributed to a particular disease. This hospital day ratio acted as an anchor in the estimation of medical costs. Hospitalization data are collected annually and are standardized within the same definition (days in hospital), and they thus permit comparisons across diseases. Similar annual data are not available for drug use or most other categories of spending, such as medical durable products (eg, wheelchairs). Moreover, hospitalizations are the most expensive category of medical care, accounting for $40 \%$ of medical costs (20). Physicians' services are second at $22 \%$ (20).

Most studies assume that spending on all other direct costs is proportional to days in the hospital. This assumption is controversial for most occupational diseases, however. For example, asthma generates a great amount of outpatient care but little, by comparison, inpatient care (21). We adjusted for these varying expenses as indicated by our inpatient and outpatient categories. Our adjustments represent an improvement over prior cost studies.

Our "top-down" approach began with an estimate of national expenditures on medical care-USD 1210.7 billion (USD 1.2107 trillion) or $13.0 \%$ of the gross domestic product in 1999 (20). This year (1999) was the latest year for which the critical information on out-ofpocket expenses and dental services were available at the time of our study. This USD 1.2107 trillion is equivalent to spending USD 4358 per person. The federal government contributes roughly $33 \%$, state and local expenditures account for $11 \%$, and direct out-of-pocket expenditures contribute $18 \%$. The remainder, $38 \%$, comes from private health insurance and health maintenance organizations (HMO). These USD 1210.7 billion in health-care expenditures include payments for hospitalizations, physician visits, nursing-home care, drugs, medical supplies, and dental services, among others. They also include public health-care expenditure, such as the construction of hospitals and offices, government public health activities, and research, as well as program administration and the net cost of health insurance. We included these latter expenditures on the grounds that, without these occupational diseases, some portion of 
these expenditures would not be necessary. These costs are also accounted for in the incidence method, which multiplies estimates of average costs by, for example, the number of surgeries. Average cost estimates include a component for "fixed" costs, including the amortized cost of buildings.

We excluded dental services (USD 56.0 billion), reasoning that occupational diseases should not influence dental costs. We, therefore, used USD 1210.7$56.0=1154.7$ billion when we began the calculations.

Our analysis was divided into 14 parts—one for each disease identified in table 1 . These 14 were drawn from Nurminen \& Karjalainen (3). In the description of the methods that follows, we have used cancer as the example. The same methods were applied to all 14 diseases.

Table 1 provides the age limits. Most of these limits were suggested by Nurminen \& Karjalainen (3), as well as by Markowitz in Fahs et al (2). Because of disease latency and cumulative exposure these diseases primarily affect those who are $\geq 25$ years of age. Many of the exposures can result in disease that develops during retirement. The one disease that allows a younger limit is asthma, for which we used 20 years of age (21). Asthma can be exacerbated in young workers within the first weeks or months on the job. It need not take years, as is required for other occupational diseases. We also im- posed a top age limit of 64 years for depression, circulatory diseases, and ulcers. The 64-year age limit for depression and ulcers is recommended by Nurminen \& Karjalainen (3). The 64-year age limit for circulatory diseases has been recommended by Fahs et al (1) and Leigh et al (2). However, more recently, Leigh \& Schnall (22) have suggested an upper age limit of 74 years. The codes of the ninth revision of the International Classification of Diseases (ICD-9) were drawn from Fahs et al (2) and from Nurminen \& Karjalainen (3), after the latter were converted from ICD-10 codes. The "mapped" ICD-9 codes are shown in table 1.

Our estimates relied on a formula. This formula is best illustrated with a specific example. We chose, cancer among women (ICD9-CM codes 140-209):

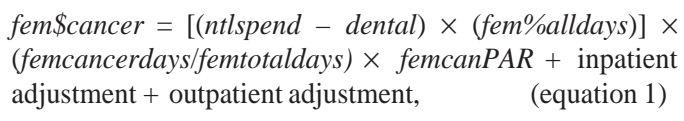

where fem\$cancer is our estimate of the medical dollars spent for occupational cancer among women, ntlspend is national spending on medical care, dental is spending on dental services, fem\%alldays is the percentage contribution of women to all hospital days for all diseases and injuries, femcancerdays is the number of days in the hospital attributed to women $\geq 25$ years of age with cancer, femtotaldays is the number of days in

Table 1. Number of days of care for discharges from short-stay hospitals according to the ICD-9-CM code of the first-listed diagnosis, gender, and age in the United States in 1999. a (ICD-9-CM = ninth revision of the International Classification of Diseases, PAR = proportionate attributable risk)

\begin{tabular}{|c|c|c|c|c|c|}
\hline \multirow[t]{2}{*}{ Disease $^{b}$} & \multirow[t]{2}{*}{ Age (years) } & \multicolumn{2}{|c|}{ Men } & \multicolumn{2}{|c|}{ Women } \\
\hline & & $\begin{array}{l}\text { Days of } \\
\text { care }^{c} \\
(\%)\end{array}$ & $\mathrm{PAR}^{\mathrm{d}}$ & $\begin{array}{l}\text { Days of } \\
\text { care }^{c} \\
(\%)\end{array}$ & PAR \\
\hline Pulmonary tuberculosis (011) & $\geq 25$ & 53048 & 0.6 & 13908 & 75 \\
\hline Pneumococcal disease (038.2) & $\geq 25$ & 42499 & 15.6 & 37397 & 10.9 \\
\hline Malignant neoplasms (140-209) & $\geq 25$ & 4070157 & 13.8 & 4483778 & 2.2 \\
\hline Dementia $(290.4,294.9)$ & $\geq 25$ & 81626 & 10 & 67891 & 1.8 \\
\hline Depressive episodes (296.21,296.22, 296.23, 296,24, 296.82, 311) & $26-64$ & 309924 & 14.6 & 418573 & 9.8 \\
\hline Nervous system disorders $(323.7,331,332,335,349.82,356,357.7,359.4)$ & $\geq 25$ & 295949 & 5.1 & 399884 & 1.7 \\
\hline \multirow[t]{2}{*}{ Grculatory diseases $(401-404,410-414,430-438,440)$} & $25-64$ & 3489759 & 14.4 & 2322124 & 6.7 \\
\hline & $25-74$ & 6010492 & 14.4 & 4595786 & 6.7 \\
\hline Pneumonia $(480,481,482,484)$ & $25-64$ & 269840 & 1.4 & 301303 & 0.3 \\
\hline Chronic obstructive pulmonary disease (490-492, 494-496) & $\geq 25$ & 1453541 & 14.0 & 2129761 & 3.8 \\
\hline Asthma (493) & $\geq 20$ & 243549 & 17.8 & 801082 & 18.4 \\
\hline Pneumoconioses and diseases due to fumes (501-506) & All ages & 7718 & 100 & 2623 & 100 \\
\hline Oryptogenic fibrosing alveolitis (516) & $\geq 25$ & 40231 & 25.3 & 40847 & 3.2 \\
\hline Gastric and duodenal ulcer $(531,532)$ & $25-64$ & 199763 & 29.0 & 100997 & 29.0 \\
\hline Chronic renal failure and nephritic syndrome $(582,585,586,590,593)$ & $\geq 25$ & 336353 & 17.6 & 412614 & 2.3 \\
\hline \multicolumn{6}{|c|}{$\begin{array}{l}\text { a Source: National Center for Health Statistics. } \\
\text { b Code of the ICD-9-CM given in parentheses. } \\
\text { c These columns present days of care for men and women for all diseases and injuries for persons in the age brackets in column } 2 \text {. These are not days } \\
\text { of care for only job-related conditions. Days of care for job-related conditions can be estimated by multiplying a PAR with a days-of-care value. } \\
\text { d These columns present the PAR for job-related conditions. They have been drawn from Nurminen \& Karjalainen (3). The female PAR of } 75 \% \text { for } \\
\text { tuberculosis is not a misprint. }\end{array}$} \\
\hline
\end{tabular}


the hospital attributed to all diseases and injuries in the United States (US), and femcanPAR is the PAR for women with cancer.

The numbers for the first part of equation 1 were as follows: (USD 1210.7-56.0) $\times 0.57085 \times(4483778 /$ $91409000) \times 0.022+$ inpatient adjustment + outpatient adjustment. Hospital days were drawn from the National Hospital Discharge Survey (23).

The hospital days ratio in equation 1 (femcancerdays(femtotaldays) assumed that all hospital days have equal costs, regardless of the disease (eg, circulatory disease or cancer or asthma). It also assumed that all nonhospital (outpatient) costs were proportional to hospital days. Since this simple method is widely used (1, $2,7)$, we applied it to our data on the 14 diseases. However, we adjusted to reflect the varying costs of medical care for each of the 14 diseases.

The inpatient adjustment relied on data from the Agency for Healthcare Research and Quality (24). This agency maintains cost data per disease per hospital day on a website and in its research note series (25). We calculated that, on the average, a hospital day for cancer costs $119.517 \%$ of the typical hospital day for all diseases and injuries; that is, cancer was roughly $19.5 \%$ more expensive than the average cost. We multiplied the 0.19517 by the percentage of the total United States medical care costs attributed to hospitalizations (less dental care): 0.3385 . Therefore $33.85 \%$ of the total costs arose from hospital care. The product $(0.19517 \times 0.3385)$ was then multiplied by the first half of equation 1 (USD $1210.7-56.0) \times 0.57085 \times 0$ (femcancerdays/femtotaldays $) \times 0.022$ ). We referred to this procedure as the inpatient care adjustment. This adjustment was added (for our cancer example) because the average daily cancer charge exceeded the average daily charge for all diseases and injuries.

The outpatient adjustment relied on the physician visit data available on cancer from the authoritative Ambulatory Care Visits series of the National Center for Health Statistics (26). We assumed that physician visits and "other" outpatient visits served as a proxy for all professional services, except dental costs. These services comprise $29.49 \%$ of spending, excluding dental services (20). We did not include emergency department visits in this ratio calculation since they can result in a hospital admission. We would therefore be doublecounting. For malignant neoplasms, we used outpatient visits with all ICD-9 codes 140-209 (27).

The ratio for hospital days for men and women with ICD-9 codes 140-209 to all hospital days was 0.06738 . The ratio of outpatient visits (excluding emergency visits) for ICD codes 140-209 to all visits for all codes was 0.03289 . The ratio of these ratios was 0.03289:0.06738 $=0.4446$. Our adjustment, for women, was (USD 1210.7-56.0) $\times 0.57085 \times$ femcancerdays/femtotaldays) $\times 0.022 \times 0.2949 \times(1-0.4446)$ or USD $0.711329 \times 0.2949$ $\times 0.5554=$ USD 0.11651 . Since the contribution of cancer to visits was less than the contribution of cancer to hospital days, this USD 0.11651 was subtracted.

\section{Results}

Appendix 1 presents our calculations for the medical costs of the 14 occupational diseases. Even more detail is available via email from the first author (pleigh@ucdavis.edu). Table 2 combines the more important estimates from appendix 1.

Diseases were ranked in order of costs as follows: circulatory diseases in the age group of $\leq 64$ years (USD 4.66 billion), cancer (USD 4.30 billion), COPD (USD 2.20 billion), asthma (USD 1.48 billion), ulcers (USD 0.52 billion), chronic renal failure (USD 0.45 billion), depression (USD 0.39 billion), nervous system disorders (USD 0.144 billion), pneumococcal diseases (USD 0.073 billion), cryptogenic fibrosing alveolitis (USD 0.07034 billion), pulmonary tuberculosis (USD 0.07028 billion), pneumoconiosis (USD 0.06172 billion), dementia (USD 0.0397 billion), and pneumonia (USD 0.02468 billion). These sum to USD 14.48 billion. Men and women contributed USD 10.65 billion and USD 3.83 billion, respectively. Men contributed more costs than women for 12 diseases. However, for tuberculosis and asthma, women contributed more costs than men.

The bottom row of table 2 provides the total estimate when the age limit for circulatory diseases was increased to 74 years. The "age 74-year" total was USD 18.13 billion, for which men contributed USD 13.23 billion and women contributed USD 4.91 billion.

Table 3 presents the results of the inpatient and outpatient adjustments, which vary by disease. For example, the following diseases generated more inpatient hospital costs per hospital stay than most diseases and injuries (whether or not job-related): cancer, nervous system disorders, circulatory diseases, pneumoconiosis, cryptogenic fibrosing alveolitis, and ulcers. By contrast, only one disease, asthma, generated disproportionately high outpatient visits compared with all other diseases and injuries (whether or not job-related).

This last result - that so few diseases on our list generated disproportionately high outpatient costs—reflects the fact that so few physician visits result in hospitalization. Most physician visits are due to diseases and injuries that do not require hospitalization (eg, colds, flu). Our method relied heavily on hospital days because these are the largest categories of costs. But our results suggested that this method overestimated costs associated with outpatient visits, on the average. The combined outpatient adjustment was -USD 1.87 billion 
Table 2. Medical costs in the United States for 14 occupational diseases in 1999.

\begin{tabular}{llll}
\hline & & Costs (USD, billions) \\
\cline { 2 - 4 } Disease or condition & Men & Women & Total \\
\hline Pulmonary tuberculosis (ages $\geq 25$ years) & 0.002091 & 0.068179 & 0.07027 \\
Pneumococcal disease (ages $\geq 25$ years) & 0.0456 & 0.02801 & 0.07361 \\
Malignant neoplasms (ages $\geq 25$ years) & 3.65454 & 0.64182 & 4.29636 \\
Dementia (ages $\geq 25$ years) & 0.034272 & 0.005400 & 0.039672 \\
Depressive episodes (ages $\geq 25$ years) & 0.206534 & 0.187224 & 0.393758 \\
Nervous system disorders (ages $\geq 25$ years) & 0.09921 & 0.04468 & 0.14389 \\
Girculatory diseases (ages 25-64 years) & 3.56059 & 1.10246 & 4.66305 \\
Circulatory diseases (ages 25-74 years) & 6.1313 & 2.18177 & 8.31307 \\
Pneumonia (ages 25-64 years) & 0.01989 & 0.00479 & 0.02468 \\
Chronic obstructive pulmonary disease (ages $\geq 25$ years) & 1.8561 & 0.34377 & 2.19987 \\
Asthma (ages $\geq 20$ years) & 0.33573 & 1.14256 & 1.47829 \\
Pneumoconioses and diseases due to fumes (all ages) & 0.04592 & 0.01577 & 0.06169 \\
Oryptogenic fibrosing alveolitis (ages $\geq 25$ years) & 0.06232 & 0.00799 & 0.07031 \\
Gastric and duodenal ulcers (ages 25, 64 years) & 0.3446 & 0.17425 & 0.5185 \\
Chronic renal failure (ages $\geq 25$ years) & 0.3869 & 0.06201 & 0.44891 \\
\hline Total with circulatory diseases for ages 25-64 years & 10.654297 & 3.828913 & 14.48321 \\
Total with circulatory diseases for ages 25-74 years & 13.22501 & 4.90822 & 18.13323 \\
\hline
\end{tabular}

Table 3. Inpatient and outpatient adjustments for 1999.

\begin{tabular}{|c|c|c|c|c|c|c|}
\hline \multirow{3}{*}{ Disease or condition } & \multicolumn{6}{|c|}{ Costs (USD, billions) } \\
\hline & \multicolumn{2}{|l|}{ Men } & \multicolumn{2}{|c|}{ Women } & \multicolumn{2}{|c|}{ Total } \\
\hline & Inpatient & Outpatient & Inpatient & Outpatient & Inpatient & Outpatient \\
\hline Pulmonary tuberculosis (ages $\geq 25$ years) & -0.000139 & -0.00007 & -0.004527 & -0.002294 & -0.00466 & -0.002364 \\
\hline Pneumococcal disease (ages $\geq 25$ years) & -0.00068 & -0.00146 & -0.00052 & -0.0009 & -0.0012 & -0.00236 \\
\hline Malignant neoplasms (ages $\geq 25$ years) & +0.26759 & -0.6639 & +0.0470 & -0.11651 & +0.31459 & -0.78041 \\
\hline Dementia (ages $\geq 25$ years) & -0.010998 & -0.01359 & -0.001337 & -0.00208 & -0.012335 & -0.01567 \\
\hline Depressive episodes (ages $\geq 25$ years) & -0.06296 & -0.056803 & -0.057076 & -0.05149 & -0.120036 & -0.108293 \\
\hline Nervous system disorders (ages $\geq 25$ years) & +0.00097 & -0.01060 & +0.00044 & -0.00478 & +0.00141 & -0.01538 \\
\hline Circulatory diseases (ages 25-64 years) & +0.48133 & -0.5445 & +0.1490 & -0.1687 & +0.63033 & -0.7132 \\
\hline Grculatory diseases (ages 25-74 years) & +0.829006 & -0.9376 & +0.25663 & -0.3309 & +1.085636 & -1.2685 \\
\hline Pneumonia (ages 25-64 years) & -0.00128 & -0.0061 & -0.00026 & -0.00145 & -0.00154 & -0.00755 \\
\hline Chronic obstructive pulmonary disease (ages $\geq 25$ years) & -0.11669 & -0.1778 & -0.02161 & -0.03293 & -0.1383 & -0.21073 \\
\hline Asthma (ages $\geq 20$ years) & -0.01794 & +0.041415 & -0.06103 & +0.14114 & -0.07897 & +0.18255 \\
\hline Pneumoconioses and diseases due to fumes (all ages) & +0.00072 & -0.01030 & +0.00021 & -0.003546 & +0.00093 & -0.013846 \\
\hline Oryptogenic fibrosing alveolitis (ages $\geq 25$ years) & +0.00237 & -0.01367 & +0.0003 & -0.00175 & +0.00267 & -0.01542 \\
\hline Gastric and duodenal ulcers (ages 25, 64 years) & +0.02043 & -0.09358 & +0.01033 & -0.04732 & +0.03076 & -0.14090 \\
\hline Chronic renal failure (ages $\geq 25$ years) & -0.01536 & -0.02469 & -0.002462 & -0.00396 & -0.017822 & -0.02865 \\
\hline Total with circulatory diseases for ages 25-64 years & +0.547363 & -1.57564 & +0.058458 & -0.29657 & +0.605821 & -1.87221 \\
\hline Total with circulatory diseases for ages $25-74$ years & +0.895039 & -1.96874 & +0.166088 & -0.45877 & +1.061127 & -2.42751 \\
\hline
\end{tabular}

(for the 64-year age limit on circulatory diseases). This value was roughly three times the inpatient underestimate of +USD 0.606 billion (for the 64-year age limit on circulatory diseases). In the last row of table 3, which includes the 74-year age limit for circulatory diseases, the total inpatient adjustment is -USD 2.43, and the outpatient adjustment is +USD 1.06.
The PAR were somewhat contentious. Previous researchers have suggested a range for the PAR. Table 4 presents a sensitivity analysis that allows consideration of a number of different PAR. Possible "upper-limit" PAR are considered at the top of table 4, and "lower-limit" PAR are shown in the bottom half of the same table. We only considered varying PAR for 
Table 4. Sensitivity analysis for 1999. (PAR = population attributable risk)

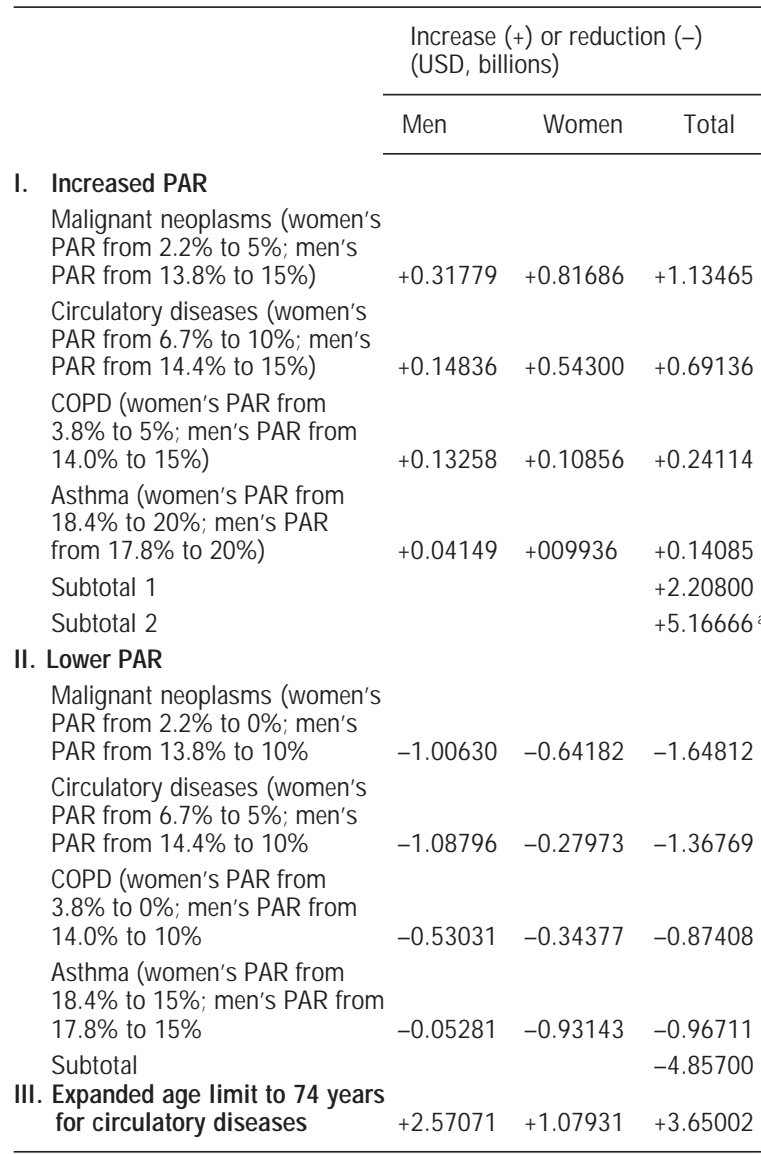

a Excludes estimate for circulatory diseases in the 64-year age-limit group but includes estimate for circulatory diseases in the 74-year age limit group.

the diseases with contributions of at least USD 1.0 billion. Also included in table 4 is the effect on the estimates resulting from the 74-year age limit for circulatory diseases.

The sensitivity analysis allowed the PAR to be "rounded up" or "rounded down" to the closest increment of $5 \%$ (ie, $0 \%, 5 \%, 10 \%, 15 \%, 20 \%$ ). If we allow only the 64-year age limit for circulatory diseases, the upward adjustments add USD 2.2 billion to our estimate. If we allow a 74-year age limit, the upward adjustment is USD 5.17 billion. The downward adjustments combined would total USD 4.86. Our estimates (assuming a 74-year limit for the upper limit) ranged from USD 9.6 to 19.7 billion.

\section{Discussion}

We estimated the medical costs of 14 occupational diseases to be USD 14.2 billion in 1999 with a range of USD 9.6 to 19.4 billion. Our estimates improved on
Table 5. Direct medical costs by disease or condition in 1999. ${ }^{\mathrm{a}}(\mathrm{COPD}=$ chronic obstructive pulmonary disease, $\mathrm{HIV}$ = human immunodeficiency virus)

\begin{tabular}{lrl}
\hline Disease or Condition & $\begin{array}{c}\text { Cost (USD, } \\
\text { billions) }\end{array}$ & \multicolumn{1}{c}{ Source } \\
\hline Girculatory diseases & 145.2 & Hodgson, et al, 1999 (10) \\
Obesity & 59.1 & Wolf, et al, 1998 (16) \\
Cancer & 46.0 & Thom, 1996 (12) \\
Diabetes & 18.7 & Thom, 1996 (12) \\
COPD & 18.3 & Sullivan, et al, 2000 (17) \\
Fourteen occupational diseases & 14.2 & This study \\
Pneumonia & 11.1 & Nederman, et al, 1988 (19) \\
HIV & 10.0 & Bozzette, et al, 1998 (18) \\
Rheumatoid arthritis & 7.2 & Yelin, 1996 (11) \\
Asthma & 6.1 & Smith, et al, 1997 (15) \\
Gunshot injuries & 2.7 & Cook, et al, 1999 (28) \\
Epilepsy & 2.3 & Begley, et al, 2000 (14) \\
Hepatitis C & 1.9 & Leigh, et al, 2001 (6) \\
\hline
\end{tabular}

a Each original estimate was adjusted for inflation so that all costs could be expressed in 1999 in US dollars. We used the medical care index from the consumer price index, all urban consumers, US Census Bureau, statistical abstract of the United States for 2000 (120th edition), Washington, DC, 2000.

b Our calculation: cost for 2 months = USD 5.1 ; cost for 6 months = USD 6.7. Therefore, 6.7-5.1=USD 1.6 for 4 months. Therefore, $1.6 \times(6 / 4)$ $=2.4$. And 6.7+2.4=USD 9.1 for 12 months in 1996. In 1999, this would be $=$ USD 10.0. The costs of care for persons seen during the first 2 months of 1996 wereUSD 5.1; the costs for persons seen during the first 6 months were USD 6.7. The increase drops there were only data on very sick people in the first 2 months.

prior estimates in that we used the most recent cost data, provided estimates for men and women separately, included several diseases excluded from prior studies (tuberculosis, pneumococcal disease, dementia, depression, pneumonia, alveolitis, and ulcers), expanded the circulatory disease age limit to 74 years, separated asthma and COPD, included special adjustments for inpatient and outpatient care, and relied on data on age-specific hospital days from the National Center for Health Statistics as opposed to estimating the days on the basis of assumptions regarding age distribution.

These are large dollar amounts. To put them in perspective, we reviewed some cost-of-illness studies and gleaned their data on medical or direct costs only. The review is summarized in table 5. We adjusted for inflation for each of these sources to express all amounts in 1999 in US dollars. Diseases were ranked according to costs.

All circulatory diseases, whether or not job-related, generated the greatest costs, USD 145.2 billion (table 5 ). The medical costs related to obesity and cancer are next on the list at USD 59 and 46 billion. Two diseases (diabetes, USD 18.7, and COPD, USD 18.3) generated costs that are at the high end of the range of our estimates for 14 occupational diseases. The medical cost of AIDS (acquired immunodeficiency syndrome), USD 10 billion, is at the low end of our estimates. Finally, 
several diseases and conditions generated fewer costs than our lowest limit (ie, asthma, rheumatoid arthritis, gunshot injuries, epilepsy, and hepatitis $\mathrm{C}$ ).

A prior study estimated costs for occupational COPD and asthma. However, the study did not provide separate estimates for men and women. The medical costs for COPD were a little higher (USD 2.8 billion) than our estimate (USD 2.2 billion) due to the assumed $15 \%$ PAR in the prior study versus the $4 \%$ (women) and $14 \%$ (men) assumed PAR in our study. The asthma estimates were remarkably similar across the two studies after inflation was accounted for.

There were several limitations to our study. First, a consensus on the PAR was difficult to obtain. The PAR we used were drawn largely from the exhaustive study by Nurminen \& Karjalainen (3). Nurminen \& Karjalainen cite 340 references. Yet most of these studies were not conducted on US populations. We used international PAR to generate our US cost estimates. But these international studies appear to be more comprehensive than the purely US studies. The latter, for example, tend to ignore ulcers and depression. Nevertheless, in general, our PAR compare favorably with the ranges suggested by Markowitz in Fahs et al (1) and Leigh et al (2), for example, cancer (6\% to $10 \%)$, circulatory diseases (5\% to $10 \%$ ), COPD (10\%), renal disorders (1\% to $3 \%$ ), and nervous system disorders (1\% to $3 \%$ ). In addition, our PAR also compare favorably with recent work on COPD (15\%), asthma (15\%), and circulatory diseases $(15 \%)(21,22)$. Moreover, we used linear estimating techniques. Therefore our readers can generate their own estimates using different PAR. (See the first "advantage" listed later in this discussion.) Finally, we clearly listed the diseases included. Some readers may want depressive episodes excluded, for example. Alternative estimates can be generated depending on the list of diseases most preferred by the reader.

Second, whereas we used cost data from reliable sources-the National Center for Health Statistics and the Agency for Healthcare Research and Quality-these costs themselves are estimates. Moreover, many prices in the medical care sector are not established in free markets. Because some prices are imposed by government and because market imperfections are widespread, some economists do not regard even the data from the National Center for Health Statistics and the Agency for Healthcare Research and Quality as "true" costs (28). Nevertheless, the data of these organizations are widely cited in medical journals and even in economic journals. They are the best data we have on actual expenditures.

A third limitation was that we did not estimate indirect costs; it was beyond the scope of our study. But direct medical costs, such as we have estimated, are less controversial than indirect costs. We believe our comparisons to medical costs (only) of other diseases and injuries in table 5 are unique in the literature.

A fourth limitation was that our estimates did not include job-related osteoarthritis (29). The idea of jobrelated osteoarthritis is that an on-the-job injury to the knee at 40 years of age, say, can result in osteoarthritis in that knee at 70 years of age. But only one study has estimated these costs (29). Moreover, whereas the idea of job-related osteoarthritis is accepted by osteoarthritis researchers (30-34), it has not been widely appreciated by occupational medicine researchers.

Fifth, we were limited by relying on the diseases for which occupational medicine researchers suggest PAR, and virtually all of these apply to mortality. As a result, PAR are generally not available for nonfatal diseases. The Bureau of Labor Statistics provides estimates for additional job-related illnesses and conditions, most of which are nonfatal. These include, for example, dermatitis, hearing loss, and carpal tunnel syndrome. We do not explicitly account for the estimates in the annual survey of the Bureau of Labor Statistics. However, there is some overlap between the numbers of the Bureau and our PAR regarding circulatory diseases, COPD, asthma, pneumoconiosis, cancer, mental disorders, and nervous system disorders. Together, these account for about $22 \%$ of the totals given by the Bureau of Labor Statistics for occupational illnesses. We therefore captured $22 \%$ of the Bureau numbers in our estimates. Second, the PAR estimates of disease accounted for $90 \%$ of all occupational disease costs in a prior study (1-2). Third, the appropriate incidence methodology for estimating costs for these cases from the Bureau of Labor Statistics is not the same as the PAR prevalence method and was not in the scope of this study.

A sixth limitation pertained to administration costs. In the prior study, we adjusted upward the administration costs of the National Center for Health Statistics to reflect some economists' objections to government estimates of administration. But these objections are themselves somewhat controversial. One of the economists would like to include time spent by patients waiting to see the physician as an administrative cost (35). In any case, virtually all cost-of-illness studies that include administrative costs use the administrative cost numbers of the National Center for Health Statistics "as is". We adopted this method in our present study to allow a fair comparison with the estimates in table 5 .

An advantage of our method was that estimates were derived from linear calculations. As a result, any estimate in our tables can be adjusted for a different PAR simply by multiplying by the ratio of the different PAR to the PAR we assumed. For example, to derive an estimate for a 5\% PAR for women with cancer, our 
estimate of USD 0.64182 in table 2 must be multiplied by $5 / 2.2$, where 2.2 is the PAR we originally assumed.

There are two implications for our research. First, most of these costs were not likely to be borne by workers' compensation insurers and businesses responsible for job exposures leading to the disease. Workers' compensation claims would likely be accounted for in the annual survey estimates of the Bureau of Labor Statistics. Again, only roughly $10 \%$ of all medical costs for occupational illness correspond to cases in this annual survey $(1,2)$. Many of these 14 diseases do not manifest themselves until retirement. But workers' compensation insurers in the United States rarely, if ever, pay for the medical care of retired persons. As a result, much of these costs were shifted from workers' compensation insurers to Medicare (ie, the taxpayers). This is a classic case of what economists refer to as a "negative externality". Under these conditions, businesses responsible for the exposure do not pay for the true cost of these exposures. As a result, an inefficient number (too many) of these exposures will occur in "the market". One way to reduce the externality is to tax the industries most responsible for these diseases. The proceeds of the tax could be paid directly to Medicare. This approach provides an incentive to industry to reduce exposures while lessening the financial burden on Medicare, and thus the taxpaying public. Interestingly, workers' compensation schemes in most European countries do cover costs of some occupational diseases, notably cancer, during retirement.

Second, these estimates are large. Occupational disease costs are on par with the costs of diabetes, COPD, pneumonia, and AIDS. The research, medical, and public attention to occupational diseases appears to be significantly less than the attention to any of these four diseases.

In conclusion, we have estimated the medical costs associated with 14 occupational diseases-the lion's share of all occupational diseases. We have attempted to be as transparent as possible with our methodology to increase the understanding of details of the calculations.

\section{Acknowledgments}

Phillippa Savage and Dina McHugh provided programming assistance.

Grant support was received from the National Institute for Occupational Safety and Health (OH03750-01 and $\mathrm{OH} 07338-01)$.

\section{References}

1. Fahs MC, Markowitz SB, Leigh JP, Shin C-G, Landrigan PJ. A National estimate of the cost of occupationally related disease in 1992. Ann NY Acad Sci 1997;837:440-55.

2. Leigh JP, Markowitz SB, Fahs MC, Landrigan PJ, Costs of occupational injuries and illnesses. Ann Arbor (MI): The University of Michigan Press; 2000.

3. Nurminen M, Karjalainen A. Epidemiologic estimate of the proportion of fatalities related to occupational factors in Finland. Scand J Work Environ Health 2001;27(3):161-213.

4. US Bureau of Labor Statistics. News release: workplace injuries and illnesses in 1999. Washington (DC): US Department of Labor; 2000. 12 December 2000; http://www.bls.gov/iif/ home.htm.

5. Leigh JP, Markowitz SB, Fahs MC, Shin C-G, Landrigan PJ. Occupational injury and illness: estimates of costs, mortality and morbidity. Arch Int Med 1997;157:1557-68.

6. Leigh JP, Bowlus CL, Leistikow BN, Schenker MB. Costs of hepatitis C. Arch Int Med 2001;162(18):2231-7.

7. Rice DP, Hodgson TA, Kopstein AN. The economic costs of illness: a replication and update. Health Care Financ Rev 1985;7(1):61-80.

8. Smith DH, Malone DL, Lawsen KA, Okamoto LJ, Buttista C, Saunders WB. A national estimate of the economic costs of asthma. Am J Respir Crit Care Med 1997;156:787-93.

9. Scitovsky AA, Rick DP. Estimates of the direct and indirect costs of AIDS in the US, 1985, 1987, 1991. Public Health Rep 1987;102(1):5-17.

10. Hodgson TA, Cohen AJ. Medical expenditures for major diseases, 1995. Health Care Financ Rev 1999;21(2):119-64.

11. Yelin E. The costs of rheumatoid arthritis: absolute, incremental, and marginal estimates. J Rheumatol 1996;23:47-51.

12. Thom TJ. Economic costs of neoplasms, arteriosclerosis, and diabetes in the United States. In Vivo 1996;10(2):255-9.

13. Walsh JK, Engelhardt CL. The direct economic costs of insomnia in the United States for 1995. Sleep 1999;22:386-93.

14. Begley CE, Famulari M. Annegers JF, Lairson DR, Reynolds TF, Coan S, et al. The cost of epilepsy in the United States: an estimate from population-based clinical and survey data. Epilepsia 2000;41(3):342-51.

15. Smith DH, Malone DC, Lawson KA, Okamoto LJ, Battista C, Saunders WB. A national estimate of the economic costs of asthma. Am J Respir Crit Care Med 1997;156(3):787-93.

16. Wolf AM, Colditz GA. Current estimates of the economic cost of obesity in the United States. Obes Res 1998;6(2):97-106.

17. Sullivan SD, Ramsey SD, Lee TA. The economic burden of COPD. Chest 2000;117(2):5-9.

18. Bozzette SA, Berry SH, Duan NJ, Frankel MR, Leibowitz AA, Lefkowitz D, et al. The care of HIV-infected adults in the United States. New Engl J Med 1998;339(26):1897-1904.

19. Niederman MS, McCombs JS, Unger AN, Dumar A, Popovian $\mathrm{R}$. The cost of treating community-acquired pneumonia. Clin Ther 1998, 20(4):820-37.

20. Eberhardt MS, Ingram DO, Makac DM. Health, United States, 2001, with urban and rural chartbook. Hyattsville (MD): National Center for Health Statistics; 2001.

21. Leigh JP, Romano PS. Schenker MB, Kriess K. Costs of occupational COPD and asthma. Chest 2002;121(1):264-72.

22. Leigh JP, Schnall P. Costs of occupational circulatory disease. In: Schnall PL, Belkic KL, Landbergis PA, Baker DB, editors. The workplace and cardiovascular disease. Philadelphia (PA): Hanley \& Belfus Inc; 2000. p 257-67. Occupational medicine: 
state of the art reviews, vol 15.

23. National Center for Health Statistics. National hospital discharge survey multi-year data file, 1977-1999. Rockville (MD): National Center for Health Statistics; 2001. CD-ROM series 13, no 19A, ASCII data, March 2001.

24. Agency for Health Care Policy and Research and Agency for Healthcare Research and Quality. Clinical classifications for health policy research: hospital inpatient statistics. Rockville (MD): Agency for Health Care Policy and Research and Agency for Healthcare Research and Quality; 1998. HCUP-3 research note; publication no 98-0049.

25. Agency for Healthcare Research and Quality. Health care cost and utilization project, 1999. http://www.ahcpr.gov/data/hcup/ his96, accessed 1 August 2001.

26. National Center for Health Statistics. Ambulatory care visits. Washington (DC): US Government Printing Office; 1998. Vital and health statistics, series 13(134).

27. Schappert SM. Ambulatory care visits to physicians offices, hospital outpatient departments, and emergency departments: US, 1997. Washington, (DC): US Government Printing Office; 1999. Vital and health statistics, series13(143).

28. Cook PJ, Lawrence BA, Ludwig J, Miller TR. The medical costs of gunshot injuries in the United States. JAMA 1999;282(5):447-54.
29. Leigh JP, Seavey W, Leistikow B. Estimating the costs of job related arthritis. J Rheumatol 2001;28(7):1647-54.

30. Anderson J, Felson DT. Factors associated with knee osteoarthritis in the NHANES I survey: evidence for an association with overweight, race, and physical elements of work. Am J Epidemiol 1988;128:179-89.

31. Felson DT, Hannan MT, Naimark A, Berkeley J, Gordon G, Wilson PWF, et al. Occupational physical demands, knee bending, and knee osteoarthirtis: results from the Framingham study. J Rheumatol 1991;18:1587-92.

32. Cooper C, McAlindon T, Coggan D, Egger P, Dieppe P. Occupational activity and osteoarthritis of the knee. Ann Rheum Dis 1994;53:90-3.

33. Vingard E, Alfredson L, Goldie I, Hogstedt C. Occupation and osteoarthritis of the hip and knee: a report-based cohort study. Int J Epidemiol 1992;30:1025-31.

34. Manninen P, Heliövaara M, Riihimäki H, Suomalainen O. Physical workload and the risk of severe knee osteoarthritis. Scand J Work Environ Health. 2002;28(1):25-32.

35. Danzon PM. Hidden overhead costs: is Canada's system really less expensive? Health Aff 1992;11(1):21-43.

Received for publication: 1 November 2002 


\section{Appendix}

\section{Medical costs of occupational diseases}

\begin{tabular}{|c|c|c|c|c|c|c|c|c|}
\hline \multirow[t]{2}{*}{ Disease } & \multicolumn{2}{|c|}{$\begin{array}{l}\text { Hospital days for } \\
\text { a disease }\end{array}$} & \multicolumn{2}{|c|}{$\begin{array}{l}\text { Ratio of a disease to all } \\
\text { diseases and injuries } \\
\text { (column } 2 \text { to } 91409000 \\
\text { for females \& } 68719000 \\
\text { for males) }\end{array}$} & \multicolumn{2}{|c|}{$\begin{array}{l}\text { Costs of a disease for } \\
\text { ages } \geq 25^{\mathrm{a}} \text { (column } 4 \times \\
\text { USD 659.16/hr female } \\
\text { \& USD 495.54/hr male) }\end{array}$} & \multicolumn{2}{|c|}{$\begin{array}{l}\text { Population } \\
\text { attributable risk }\end{array}$} \\
\hline & Men & Women & Men & Women & Men & Women & Men & Women \\
\hline Pulmonary tuberculosis & 53051 & 13894 & 0.000772 & 0.000152 & 0.383 & 0.100 & 0.6 & 75 \\
\hline Pneumococcal disease & 42499 & 37397 & 0.000618 & 0.000409 & 0.306 & 0.270 & 15.6 & 10.9 \\
\hline Malignant neoplasms & 4070159 & 4483778 & 0.059229 & 0.049052 & 29.350 & 32.333 & 13.8 & 2.2 \\
\hline Dementia & 81626 & 67891 & 0.001188 & 0.000743 & 0.58861 & 0.48976 & 10 & 1.8 \\
\hline Depressive episodes & 309924 & 418573 & 0.004510 & 0.004579 & 2.23489 & 3.01829 & 14.6 & 9.8 \\
\hline Nervous system disorders & 295949 & 399884 & 0.0043067 & 0.004375 & 2.1341 & 2.8838 & 5.1 & 1.7 \\
\hline Grculatory diseases & 3489759 & 2322124 & 0.050783 & 0.02540 & 25.165 & 16.7427 & 14.4 & 6.7 \\
\hline Pneumonia & 269840 & 301303 & 0.00393 & 0.00329 & 1.9475 & 2.1686 & 1.4 & 0.3 \\
\hline Chronic obstructive pulmonary disease & 2129761 & 1453541 & 0.03100 & 0.01590 & 15.3617 & 10.4806 & 14.0 & 3.8 \\
\hline Asthma & 243599 & 801082 & 0.00354 & 0.00876 & 1.7542 & 5.7742 & 17.8 & 18.4 \\
\hline Pneumoconioses & 7718 & 2623 & 0.000112 & 0.000029 & 0.0555 & 0.0191 & 100 & 100 \\
\hline Oryptogenic fibrosing alveolitis & 40231 & 40847 & 0.000587 & 0.000447 & 0.291 & 0.295 & 25.3 & 3.2 \\
\hline Gastric \& duodenal ulcer & 199763 & 100997 & 0.002907 & 0.001105 & 1.4405 & 0.7284 & 29 & 29 \\
\hline Renal disease & 336353 & 412614 & 0.004895 & 0.004514 & 2.4257 & 2.9754 & 17.6 & 2.3 \\
\hline
\end{tabular}

\begin{tabular}{|c|c|c|c|c|c|c|c|c|}
\hline \multirow[t]{2}{*}{ Disease } & \multicolumn{2}{|c|}{$\begin{array}{l}\text { Total cost for this } \\
\text { occupational disease } \\
\text { column } 4 \times \text { column } 5 \text { ) } \\
\text { (USD, billions) }\end{array}$} & \multicolumn{2}{|c|}{$\begin{array}{l}\text { Hospital inpatient } \\
\text { adjustment } \\
\text { (USD, billions) }\end{array}$} & \multicolumn{2}{|c|}{$\begin{array}{l}\text { Outpatient adjustment } \\
\text { (USD, billions) } \\
\text { disease }\end{array}$} & \multicolumn{2}{|c|}{$\begin{array}{l}\text { Medical costs for an } \\
\text { occupational an } \\
\text { disease } \\
\text { (USD, billions) }\end{array}$} \\
\hline & Men & Women & Men & Women & Men & Women & Men & Women \\
\hline Pulmonary tuberculosis & 0.0023 & 0.075 & -0.000139 & -0.00453 & 0.00007 & -0.00229 & 0.002091 & 0.068179 \\
\hline Pneumococcal disease & 0.04774 & 0.02943 & -0.00068 & -0.00052 & -0.00146 & -0.0009 & 0.0456 & 0.02801 \\
\hline Malignant neoplasms & 4.050347 & 0.711329 & +0.26759 & +0.0470 & -0.6639 & -0.11651 & 3.65454 & 0.64182 \\
\hline Dementia & 0.05886 & 0.008816 & -0.010998 & -0.001337 & -0.013587 & -0.002079 & 0.034272 & 0.005400 \\
\hline Depressive episodes & 0.32630 & 0.29579 & -0.062963 & -0.057076 & -0.056803 & -0.05149 & 0.20534 & 0.187224 \\
\hline Nervous system disorders & 0.10884 & 0.04902 & +0.00097 & +0.00044 & -0.01060 & -0.00478 & 0.09921 & 0.04468 \\
\hline Grculatory diseases & 3.62376 & 1.12176 & +0.48133 & +0.1490 & 0.5445 & -0.1687 & 3.56059 & 1.10246 \\
\hline Pneumonia & 0.02727 & 0.0065 & -0.00128 & -0.00026 & -0.0061 & -0.00145 & 0.01989 & 0.00479 \\
\hline Ohronic obstructive pulmonary disease & 2.1506 & 0.39826 & -0.11669 & -0.02161 & -0.17781 & -0.03293 & 1.8561 & 0.34372 \\
\hline Asthma & 0.31225 & 1.06103 & -0.017937 & -0.06103 & +0.041415 & +0.14114 & 0.33573 & 1.14256 \\
\hline Pneumoconioses & 0.0555 & 0.0191 & +0.0007158 & +0.0002146 & -0.01030 & -0.003546 & 0.04592 & 0.01377 \\
\hline Oryptogenic fibrosing alveolitis & 0.073623 & 0.00944 & +0.00237 & +0.0003 & -0.01367 & -0.00175 & 0.06232 & 0.00799 \\
\hline Gastric \& duodenal ulcer & 0.41775 & 0.21124 & +0.2043 & +0.01033 & -0.02043 & -0.04732 & 0.3446 & 0.17425 \\
\hline Renal disease & 0.4269 & 0.06843 & -0.01536 & -0.002462 & -0.02489 & -0.00396 & 0.3869 & 0.06201 \\
\hline
\end{tabular}

